\title{
SPATIAL AND TEMPORAL DISTRIBUTION CHARACTERISTICS OF DROUGHT AND ITS INFLUENCING FACTORS IN HEILONGJIANG PROVINCE, CHINA FROM 1956 TO 2015
}

\author{
ZHAO, Q. ${ }^{1 *}-$ ZOU, C. H. ${ }^{1}-$ WANG, K. F. ${ }^{2}-$ GAO, Q. ${ }^{1}-$ YAO, T. ${ }^{1}$ \\ ${ }^{1}$ School of Water Conservancy and Environment, University of Jinan \\ 336 Nanxinzhuang West Road, Jinan 250022, Shandong Province, China \\ ${ }^{2}$ Shandong Institute of Geological Sciences, Jinan, Shandong Province, China \\ *Corresponding author \\ e-mail: zhaoqiang8827@ sina.com; phone: +86-135-8910-8827
}

(Received $14^{\text {th }}$ Nov 2018; accepted $16^{\text {th }}$ Jan 2019)

\begin{abstract}
In the context of global warming, extreme drought climate events show a trend of frequent occurrence. Studying the relationship between climate change and drought disasters by using the performance characteristics of climate change has become a new strategic focus of global change science. In this paper, we collected meteorological data from 14 meteorological stations from 1956 to 2015 in Heilongiiang Province and used a standard precipitation index (SPI) of meteorological drought to analyze temporal and spatial characteristics of droughts in the province. Multiple methods such as Linear regression analysis, Mann-Kendall trend test and Kriging interpolation were applied and analyzed to reveal temporal and spatial distribution patterns of drought frequency and drought intensity in different parts of the province. The results show that: (1) the precipitation in Heilongjiang Province has shown a downward trend in the past 60 years and the correlation between the monthly average precipitation and the monthly mean temperature is also apparent. (2) Since 1990s, the intensity of higher drought has escalated in the whole province and has gradually strengthened from south to north. (3) The frequency distribution of drought is the lowest in the central and southern regions, and the highest in the west. (4) The uneven precipitation, sandstorm and uneven distribution of evaporation caused by the monsoon in Heilongjiang Province are the main meteorological factors for the formation of drought in the province.

Keywords: Heilongjiang Province, drought, spatial-temporal variation, standardized precipitation index $(S P I)$
\end{abstract}

\section{Introduction}

Drought is one of the most complex and recurring natural disasters that is caused by intense and persistent shortage of precipitation. Precipitation is the main parameter that treats some environmental disasters as drought, and many other factors such as temperature, high winds, and low relative humidity also play a significant driving role in the occurrence of drought. Drought is considered to be one of the most serious natural disasters in the world because of its large spatial range and long duration, resulting in frequent occurrence of large-scale and intensive droughts around the world (Koutroulis et al., 2011; Okonkwo et al., 2013; Ngetich et al., 2014; Potop et al., 2014; Blauhut et al., 2015; Kazemzadeh and Malekian, 2016). China is deeply affected by the monsoon climate and topography, resulting in uneven distribution of water and heat leads to frequent droughts (Bi, 2007; Wang, 2007). Since 1950s, the drought disaster in northern China has been expanding and accelerating. According to the statistics, average area affected by drought in China is $1873.1 \mathrm{hm}^{2}$, with a disaster rate of $43 \%$; the grain output reduced by $25-30$ billion $\mathrm{kg}$, accounting for more than $60 \%$ of the total 
losses caused by various natural disasters. Drought brings huge economic losses to China's national economy, especially agricultural production (Jiang and An, 2011).

The problem of aridification in northern China has always been the focus of academic circles. In particular, research on two typical arid regions in North China and Northwest China has received much attention (Sun and Gao, 2000; Li et al., 2007; Hao et al., 2010; Yi et al., 2012). The study on drought in northern China has mainly concentrated on the characteristics, causes and aridification of drought evolution. For example, Spinoni et al. (2014) conducted a statistical analysis of the frequency, duration and intensity of drought events worldwide based on the SPI index. Lu et al. (2010) based on the run-length theory, extracted the drought duration and drought intensity from the comprehensive meteorological drought index sequence, and established the joint distribution of the two copula functions. Corti et al. (2011) constructed a regional drought loss assessment model. At present, the research has mostly evaluated drought and set drought research indicators from the perspective of the causes and mechanisms of drought, and the main indexes involved are standardized precipitation index (SPI), Z index, standardized precipitation evapotranspiration index (SPEI), Palmer drought index (PDSI), surface water supply index (SWSI), Wald Wasser Haushalts Modell (WAWAHAMO), water deficit index (WDI) and meteorological drought index (CI) (Mishra and Singh, 2011). Due to the complexity of the drought itself, there is currently no drought index that can comprehensively describe the changing characteristics of different types of drought. The several drought indices mentioned above have relative rationality in different geographical areas and specific timescales. Among them, the standardized precipitation index (SPI) has been accepted by meteorological scientists all over the world because of its simplicity and multi-scale advantages based only on precipitation data. It has been widely used in drought analysis and assessment work in various places (Patel et al., 2010; Kumar et al., 2016; Sujitha and Shanmugasundaram, 2017; Yang et al., 2017; Guhathakurta et al., 2018). In recent years, due to the influence of multiple factors, the frequency of drought in Heilongjiang Province has increased, and the scope of drought has expanded, spreading from the Mudanjiang area to the whole province. Except for the Heilongjiang River coast and the Greater Xing'an Mountains, most of the counties and cities have experienced different degrees of drought (Zhang et al., 2014). However, most of the studies on drought in the north have been analyzed of a regional perspective, while there are few studies on the analysis of local drought from smaller scales. In the Heilongjiang region, especially on higher latitudes, analysis of annual and seasonal drought characteristic is very infrequent. Based on the standard precipitation index (SPI), this paper implemented data analysis or geographic interpolation from interannual, interdecadal, monthly, seasonal, and abrupt changes by calculating drought frequency and drought intensity, and analyzed the spatial and temporal distribution characteristics and formation mechanism of drought in Heilongjiang Province. Through these efforts, we hope to provide a theoretical reference for the scientific understanding of regional drought characteristics and effective defense against drought disasters.

\section{Study area}

Heilongjiang Province is located in the northeastern part of China, and the total land area is $473000 \mathrm{~km}^{2}$. It is an important passage from the Asia-Pacific region to the Russian Far East and the European continent (Fig. 1). The Heilongjiang River Basin is 
mainly composed of four major river systems: Heilongjiang, Songhua River, Wusuli River and Suifen River. Regarding topography, the northwest, north and southeast of the province are relatively high, while the northeast and southwest are relatively low. Heilongjiang Province belongs to temperate continental monsoon climate with an annual average temperature between -5 and $5{ }^{\circ} \mathrm{C}$, decreasing from south to north, roughly the $0{ }^{\circ} \mathrm{C}$ contour of Nenjiang and Yichun lines (Zhang et al., 2014). The annual precipitation is mostly between 400 and $650 \mathrm{~mm}$, with more precipitation in the central mountainous area, less precipitation in the western and Northern regions, and precipitation resources are relatively stable. As an important province in Northeast China, Heilongjiang Province has a dense population and a large number of large and medium-sized cities, and it has a significant strategic position in China's political economy. However, the frequency of drought in Heilongjiang Province is at the forefront of China, and the problems caused by drought have seriously restricted the social and economic development of Heilongjiang Province.

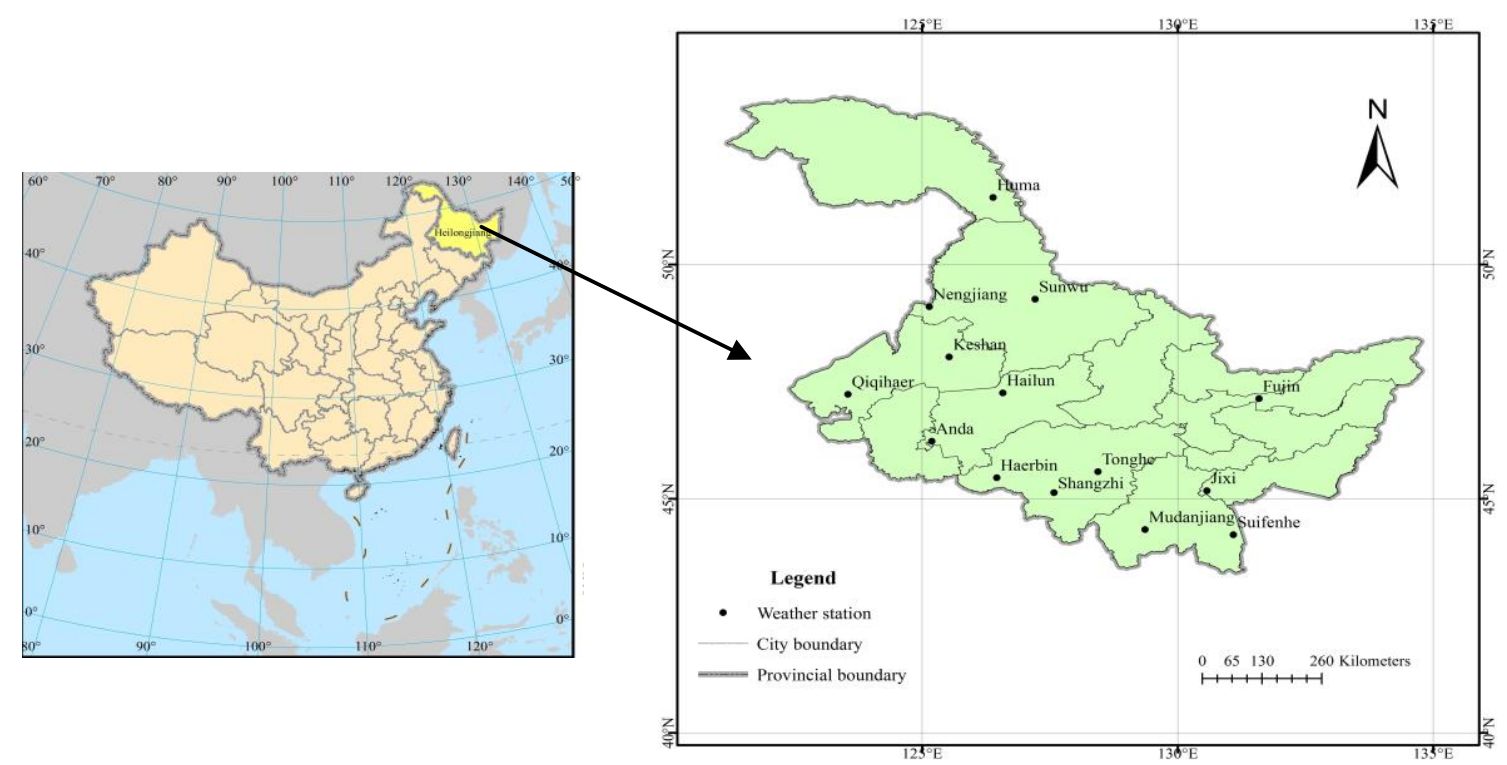

Figure 1. Location of Heilongjiang Province and distribution of typical weather stations

\section{Materials and methods}

\section{Data}

The meteorological data is provided by the China Ground International Exchange Station of China Meteorological Data Network about 14 Station which was used 1950-2015 monthly site data, including precipitation, maximum temperature, minimum temperature, average temperature, sunshine hours, wind speed and relative humidity, as well as latitude and longitude and elevation. Because bound by the site incomplete data due to site changes and lack of measurement caused by some reasons, 14 stations of Heilongjiang which has complete data were selected (Fig. 1). All data have undergone rigorous quality control and error correction. The GDEMV2 30M resolution digital elevation data used in this paper is from the Geospatial Data Cloud website. China's basic administrative divisions and water system map data come from the Resource and Environmental Science Data Center of the Chinese Academy of Sciences. 


\section{Study methods}

\section{Linear regression analysis}

Linear regression analysis describes the linear dependence between the dependent variable $y$ and the independent variable $x$. If the independent variable has only one $x$, then this linear regression is called a one-way linear regression. The task of unary linear regression is to find a linear regression equation describing the two variables $x, y$ based on several observation points $\left(x_{i}, y_{i}\right)(i=1,2,3 \ldots n)$. When judging the goodness of fit of a regression equation, the $\mathrm{R}^{2}$ decision coefficient is a significant indicator. The calculation formula of the correlation coefficient $r$ of the regression equation is (Eq. l):

$$
\mathrm{r}=\frac{\sum_{i=1}^{n}\left(x_{i}-\bar{x}\right)\left(y_{i}-\bar{y}\right)}{\sqrt{\sum_{i=1}^{n}\left(x_{i}-\bar{x}\right)^{2}} \sqrt{\sum_{i=1}^{n}\left(y_{i}-\bar{y}\right)^{2}}}
$$

The closer the absolute value of the correlation coefficient $r$ is to 0 , the worse the correlation between the two variables. Conversely, the closer the absolute value of the correlation coefficient $r$ to 1 , the better the correlation between the two variables $x$ and $y$, and the closer the linear regression equation to a flat line parallel to the $\mathrm{x}$-axis.

\section{Standardized precipitation index (SPI)}

The standardized precipitation index was proposed by Mckee in 1993 when studying the drought conditions in Colorado, USA. By first calculating the $\Gamma$ distribution probability of precipitation in a certain period, and then normalization, the cumulative precipitation frequency distribution is used to divide the drought level. Due to the standardized treatment, the SPI index eliminates the spatial and temporal distribution of rainfall, has multiple time scale characteristics, is sensitive to drought response, and can effectively reflect drought and flood conditions in different regions and different time periods (Yuan and Zhou, 2004; Kim et al., 2015). The SPI calculations for this study used the computational procedures of the University of Nebraska approved by the World Meteorological Organization. After calculating the SPI index, we can classify the drought level according to Table 1. The SPI level is above the light drought (including light drought), indicating that the drought occurred in the area.

\section{Drought evaluation indicators}

1) Drought frequency

Drought frequency refers to the ratio of the number of times the drought occurs (the level corresponding to the SPI index is above light drought) to the total number of observations during that period (Song and Singh, 2010). The calculation formula is as follows (Eq. 2):

$$
P_{i}=\frac{n}{N} \times 100 \%
$$


where: $N$ is the total time point (year, season, month) of observation data at a station, and $n$ is the number of time points (year, season, month) when drought occurs (SPI drought level is above light drought).

Table 1. Classification of standardized precipitation index drought level

\begin{tabular}{c|c|c|c}
\hline Grade & Type & Value of SPI & Extent of the effects of drought \\
\hline 1 & No drought & $-0.5<\mathrm{SPI}$ & $\begin{array}{c}\text { Precipitation is normal or higher than normal } \\
\text { years; moist surface, no signs of drought }\end{array}$ \\
\hline 3 & Moderate drought & $-1.5<\mathrm{SPI} \leq-1.0$ & $\begin{array}{c}\text { Precipitation is less than normal years; the } \\
\text { surface air dry, the soil appear moisture mild } \\
\text { deficiencies }\end{array}$ \\
\hline 4 & Serious drought & $-2.0<\mathrm{SPI} \leq-1.5$ & $\begin{array}{c}\text { Precipitation continued below normal years; } \\
\text { soil surface is dry, soil water shortage, } \\
\text { surface of plant leaves daytime wilting } \\
\text { phenomenon }\end{array}$ \\
\hline 5 & Special serious drought & $\begin{array}{c}\text { Soil appeared sustained severe lack of } \\
\text { poisture, Soil appear thicker dry soil, wilting } \\
\text { serious impact on crops and ecological } \\
\text { environment and industrial production, } \\
\text { drinking water }\end{array}$ \\
\hline
\end{tabular}

SPI: standardized precipitation index

\section{2) Drought intensity}

Drought intensity is the average of the absolute values of the SPI index at a site or time period in which drought (above SPI drought levels are above light drought) occurs over a certain period of time (Chang et al., 2012). Calculated as follows (Eq. 3):

$$
I=\frac{1}{m} \sum_{i=1}^{m}\left|S P I_{i}\right|
$$

The drought intensity was not obvious when $S_{i j}<0.5 ; 1>S_{i j} \geq 0.5$ was a mild drought; when $1.5>S_{i j} \geq 1$, it was a moderate drought; when $S_{i j} \geq 1.5$, it was severe drought.

\section{Kriging interpolation}

The Kriging interpolation method was first proposed by South African mining engineer D. G. Krige in 1951 and later developed by the famous French geographer G. Matheron. Based on the spatial autocorrelation, the Kriging method uses the original data and the semivariance function as the structure to perform unbiased optimal estimation of the unknown sample points of the regionalized variables ( $\mathrm{Li}$ et al., 2013). The Kriging method not only considers the distance, but also considers the spatial distribution of known sample points and the spatial orientation relationship with 
unknown samples through variogram and structural analysis. The interpolation formula is $(E q .4)$ :

$$
z\left(x_{0}\right)=\sum_{i=1}^{n} \lambda_{i} z\left(x_{i}\right)
$$

where: $z\left(x_{0}\right)$ is the estimated value at $x_{0}, z\left(x_{i}\right)$ is the observed value at $x_{i}, \lambda i$ is the Kriging weight coefficient, and $n$ is the number of observation points.

\section{Mann-Kendall test}

The Mann-Kendall test can be used to determine if there is an anomaly in the hydrometeorological data arranged in time series and to determine the time of the mutation. It is often used for the detection of precipitation and drought trends affected by climate change (Luo et al., 2008). Its calculation method is:

1) Calculate the order column $S_{k}$ of the sequential time series and calculate $U F_{k}$ according to the equation.

The order of the time series $\mathrm{x}$ with $\mathrm{n}$ sample sizes is listed as (Eq. 5):

$$
S_{k}=\sum_{i=1}^{k} r_{i} \quad r_{i}=\left\{\begin{array}{l}
1, x_{i}>x_{j} \\
0, x_{i} \leq x_{j}
\end{array} \quad j=1,2, \cdots, i\right.
$$

It can be seen that the order column $S_{k}$ is the cumulative number of the number of values at the $i$-th time when the value is greater than $j$. Assuming the time series are randomly independent, the statistics are defined (Eq. O):

$$
U F_{k}=\frac{s_{k}-E\left(s_{k}\right)}{\sqrt{\operatorname{Var}\left(s_{k}\right)}} \quad k=1,2, \cdots, n
$$

where: $U F_{1}=0, E\left(s_{k}\right), \operatorname{Var}\left(s_{k}\right)$ are the mean and variance of the cumulative number $S_{k}$, respectively. When $x_{1}, x_{2}, \ldots, x_{n}$ are independent of each other and have the same continuous distribution, they can be calculated by (Eq. 7):

$$
E\left(s_{k}\right)=\frac{n(n+1)}{4} \quad \operatorname{Var}\left(s_{k}\right)=\frac{n(n-1)(2 n+5)}{72}
$$

2) Calculate the order column $S_{k}$ of the reverse sequence of time, and calculate $U B_{k}$ according to the equation.

Repeat the process in 1) by the time series $\mathrm{x}$ reverse order $x_{n}, x_{n-1}, \ldots, x_{1}$, while making $U B_{k}=-U F_{k}(k=n, n-1, \ldots, 1), U B_{1}=0$. Given a significance level of $\alpha=0.05$, the critical value $U_{0.05}= \pm 1.96$. The two statistical sequence curves $U F_{k}$ and $U B_{k}$ and \pm 1.96 two critical lines are plotted on the same graph. If the value of $U F_{k}$ or $U B_{k}$ is greater than 0 , it indicates that the sequence has an upward trend. Conversely, if the value of $U F_{k}$ or $U B_{k}$ is less than 0 , it indicates that the sequence has a downward trend. If there is an intersection between $U F_{k}$ and $U B_{k}$, and the intersection is between the two critical lines, the time corresponding to the intersection is the moment when the mutation starts. If the two curves exceed the critical value, it indicates that the trend of rising or falling 
is significant, and the range exceeding the critical line is the time zone in which the mutation occurs.

\section{Results}

\section{Characteristics of drought time in Heilongjiang Province within the year}

\section{Analysis of monthly drought characteristics}

The monthly temperature and precipitation data of 14 meteorological stations in Heilongjiang Province were statistically analyzed, and the correlation curves of monthly mean temperature and monthly mean precipitation in Heilongjiang Province were plotted (Fig. 2a).
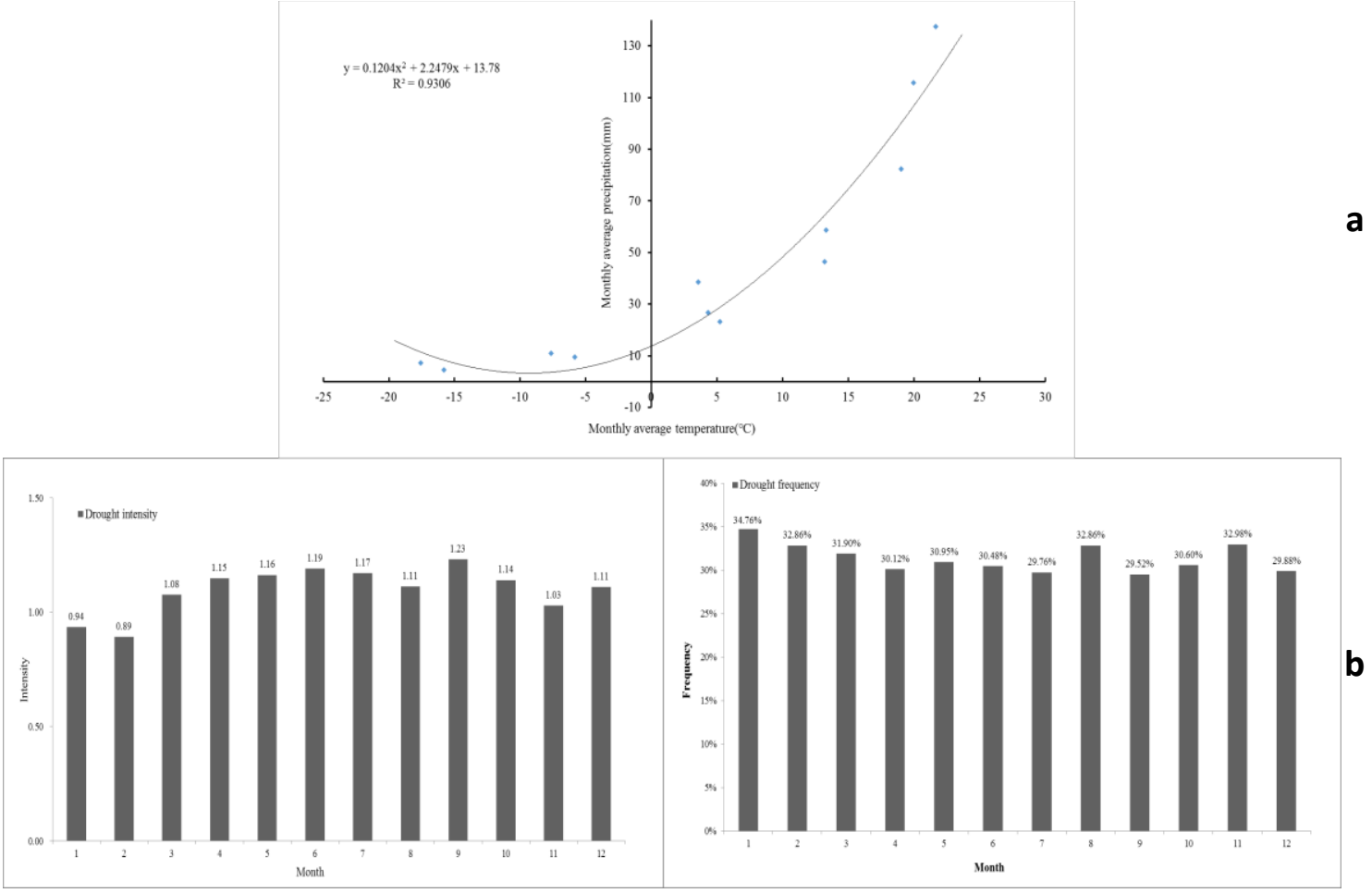

Figure 2. (a) Analysis curve of monthly mean temperature and monthly mean precipitation in Heilongjiang Province. (b) Monthly drought frequency and intensity histogram of Heilongjiang Province

It can be seen from the figure that there is a very obvious correlation between temperature and precipitation in Heilongjiang Province, and the $\mathrm{R}^{2}$ value of the correlation analysis curve reaches 0.9417. This shows that in the global warming environment, the precipitation in Heilongjiang Province is greatly affected by the temperature and even changes with the temperature. Calculate the corresponding SPI index, and classify the data. It can be seen that the monthly drought frequency in Heilongjiang Province is not much different, and fluctuates around $31 \%$. The month with the lowest frequency of drought is September, and the month with the highest frequency of drought is January. The annual intensity of the drought is relatively stable, and fluctuates between light and moderate levels. Among them, the intensity in January 
and February is 0.5 1, which is light drought. From March to December, it is between 1 and 1.5, all of which are in the middle drought. The month with the highest drought intensity is September, with a value of 1.23. The month with the lowest drought intensity was February, with a value of 0.89 (Fig. 2b). It can be seen that the drought in Heilongjiang Province is common during the year, but the intensity is relatively light and stable.

\section{Analysis of seasonal drought characteristics}

The precipitation in the four seasons of Heilongjiang Province varies greatly, showing typical monsoon precipitation. In winter, the icing period has adversely affected the water cycle of the four major river systems. Together with the combination of the northwest monsoon, the phenomenon of low precipitation in winter and high frequency of drought occurred in Heilongjiang Province. Comparing Figure 3, the seasonal drought frequency and drought intensity in Heilongjiang Province showed a reverse trend. The summer drought frequency is the lowest, but the drought intensity is the highest; the winter drought frequency is the highest, but the drought intensity is the lowest. This is due to the abundant precipitation in summer, which leads to a low frequency of drought. However, the terrain and water system in Heilongjiang Province are complex, and the summer is susceptible to the southeast monsoon, which is fragile and sensitive to drought. Moreover, global warming has caused frequent high temperatures in Heilongjiang in summer, greatly increasing the intensity of drought. Therefore, in summer, compared with winter, it is more susceptible to high temperature and forms a greater drought intensity.

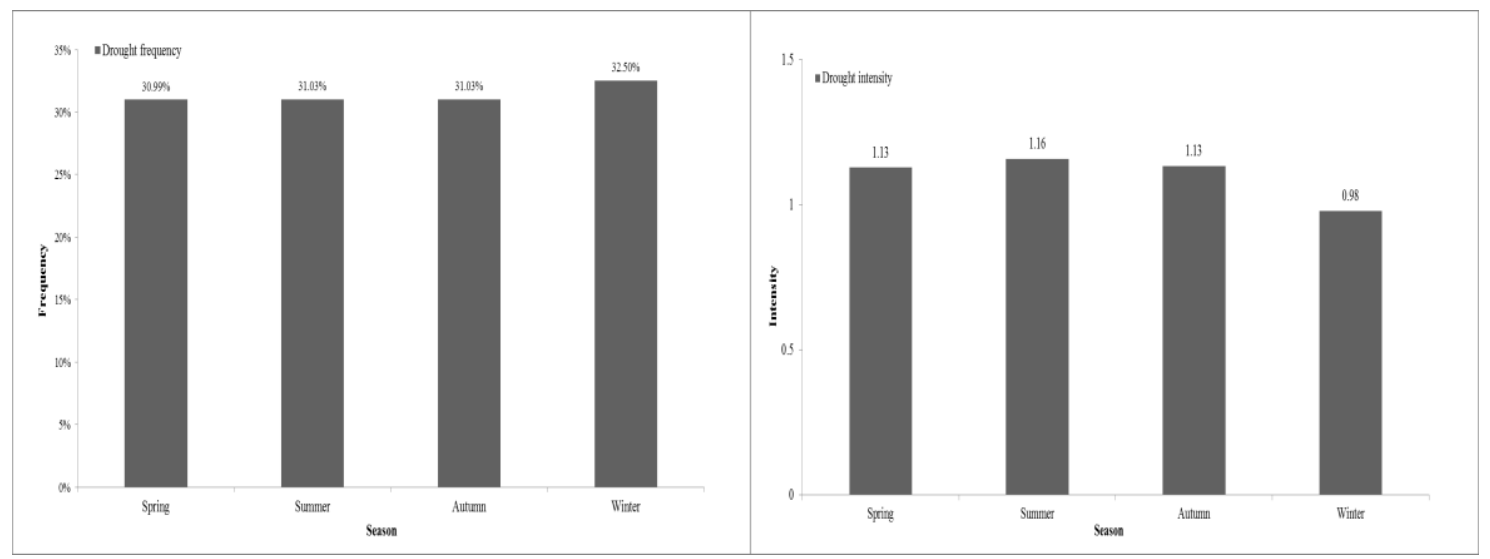

Figure 3. Heterogeneous frequency and intensity histogram of four seasons in Heilongjiang Province

\section{Analysis of interannual and interdecadal drought characteristics in Heilongjiang Province}

Time change trend analysis

Using linear regression method to analyze the trend of annual average precipitation in Heilongjiang Province, it can be seen that the precipitation in Heilongjiang Province showed a downward trend in the whole 60 years, and maintained a fluctuation of about $500 \mathrm{~mm}$, but it did not pass the significance test $(\mathrm{P}>0.05)$. The results show that the $\mathrm{R}^{2}$ 
value is only 0.0103 , which indicates that the downward trend is not significant, and the overall precipitation is relatively stable. The decadal trend map of precipitation (Fig. 4a) shows that during the ten years from 1956 to 1965, Heilongjiang Province had abundant precipitation, and the average precipitation was $572.07 \mathrm{~mm}$. However, in the 20 years after 1966, the precipitation decreased sharply, and the average precipitation between 1966 and 1975 was only $501.6 \mathrm{~mm}$. In these 20 years, the precipitation was low and lasted for a long time, which was very likely to lead to drought, and the most typical example was the national drought that occurred in 1978 1983. From 1986 to 1995, the precipitation increased and reached to $557.76 \mathrm{~mm}$. During the ten years between 1996 and 2005, interdecadal precipitation ushered in a sharp drop and fell to the lowest point in 60 years $(495.81 \mathrm{~mm})$. This is closely related to the severe drought that lasted for 4 to 5 years in North China and Northeast China around 1997. In 2006 2015, the precipitation has rebounded $(529.55 \mathrm{~mm})$, but compared with the previous stage, it still shows a downward trend.

By analyzing the variation trend of annual mean temperature in Heilongjiang Province in the past 60 years, it can be seen that the temperature in Heilongjiang Province has been fluctuating and rising in general during the past 60 years, but it did not pass the significance test $(\mathrm{P}>0.05)$. The $\mathrm{R}^{2}$ value is 0.472 , reflecting a relatively significant upward trend in temperature (Fig. 4b). Affected by global warming, the annual average temperature in Heilongjiang Province has gradually increased over the past 60 years, making the intensity of drought increasingly intensified. It can be seen from Figure 8 that in the 30 years from 1956, the annual average temperature rose slowly at a lower rate; by the decade 1976-1985, the annual average temperature has increased to $1.98^{\circ} \mathrm{C}$. In the next ten years, the temperature increased significantly at a higher rate. The average temperature in the decade from 1986 to 1995 reached $2.87{ }^{\circ} \mathrm{C}$. After that, the growth rate has slowed down noticeably. In the 20 years after 1996, the temperature in Heilongjiang Province has reached a state of constant stability, with an average temperature of $3.19^{\circ} \mathrm{C}$ in two decades.

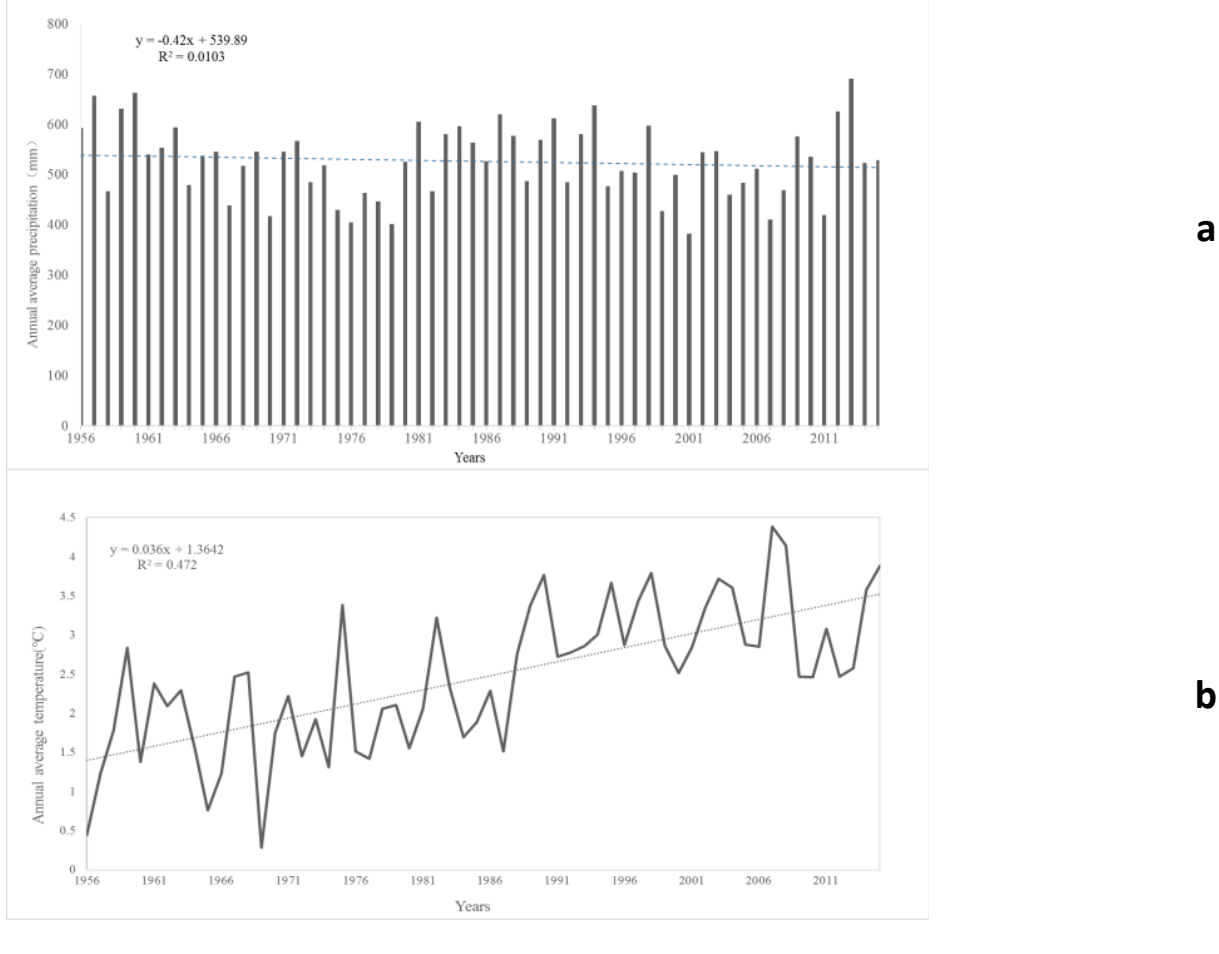




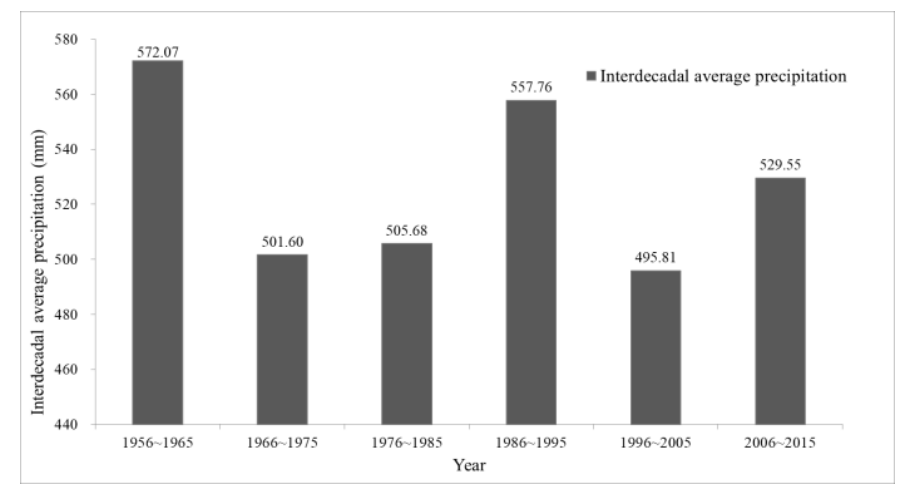

Figure 4. (a) Trends in annual average precipitation in Heilongjiang Province; (b) trends in interdecadal precipitation in Heilongjiang Province; (c) trend pattern of decadal precipitation in Heilongjiang Province

By calculating the SPI index, the drought frequency and drought index since 1956 in Heilongjiang Province were classified and calculated. It can be seen from Figure $5 a$ that the drought frequency always had large fluctuations, but it was basically the same as the overall trend of 60 years. In 1957 and 2013, there were less than 12\% of the frequency, and in 1971 and 2011 there were nearly $50 \%$ of the high frequency. It can be obviously seen from Figure $5 b$ that the intensity of drought in Heilongjiang Province has fluctuating upward in 60 years, and passed the significance test $(P>0.05)$. The intensity was between light drought and moderate drought. This was related to the persistently high temperature in Heilongjiang Province in the past 20 years and was also a response to the deterioration of the global climate.

\section{Mutation analysis}

Using the Mann-Kendall test to test the precipitation sequence from 1956 to 2015 in Heilongjiang Province, we can find that the UF curve is greater than 0 in 1956 1957 and 1959 1961, but all passed the $\alpha=0.05$ significance test, which indicates that during these two time periods, the precipitation in Heilongjiang Province has increased, but it is not significant (Fig. 5c). Between 1957 and 1959, the UF curve and UB curve intersected, and both of them were between the significant horizontal line of alpha $=0.05$. This indicates that the precipitation in Heilongjiang Province showed two abrupt changes in the trend of rising-falling-rising between 1956 and 1961. In 1961, the UF curve intersected the UB curve again, after which the UF curve began to fall less than 0 and continued to fall. In 1974, it broke the $\alpha=0.05$ significance test horizontal line, and then returned to the $\alpha=0.05$ significance test level line in 1984. This showed that 1961 was an extremely important drop point in the precipitation sequence. From 1961, the annual average precipitation in Heilongjiang Province began to decline, and the decline between 1974 and 1984 was very significant. After 1984, the UF curve was still less than zero but rising. This showed that after 1984, the precipitation in Heilongjiang was decreasing, but its rate gradually slowed down. In 1993-1995, the UF curve exceeded zero again, and the precipitation increased. However, after 1995, the UF curve continued to decrease from zero again, which represents a decreasing trend of precipitation. This drop in precipitation for the Northeast region has brought about a drought lasting about five years, the Northeast people's production and life has brought serious impact. 


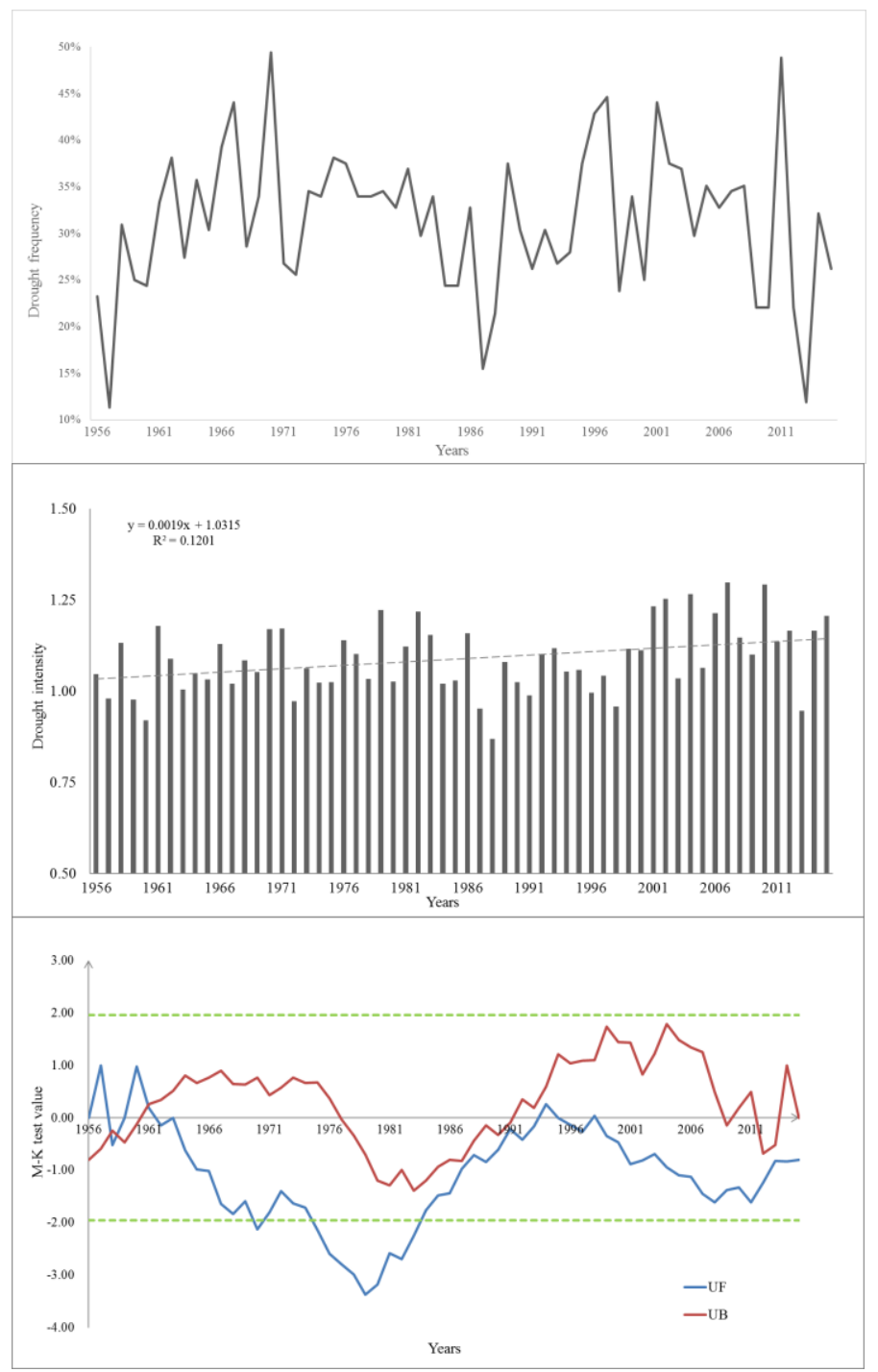

Figure 5. (a) Trend pattern of drought frequency in Heilongjiang Province from 1956 to 2015; (b) trend pattern of drought intensity in Heilongjiang Province from 1956 to 2015; (c) annual average precipitation $M-K$ test curve in Heilongjiang Province

\section{Analysis of spatial characteristics of drought in Heilongjiang Province}

\section{Interannual drought spatial distribution}

According to the SPI index of 14 weather stations, the drought frequency and drought intensity in 60 years were calculated. According to the analysis of Figure 6, the highest drought frequency in the province was centered on Qiqihaer and has spread to Anda and Harbin, with values of $33.61 \%, 32.22 \%$ and $31.94 \%$, respectively. Because of the existence of Zhangcailing and Mudanjiang in the south-central region, the drought frequency in the region centered on Tonghe River was less than $29.86 \%$. The drought frequencies in the west of Jixi and Suifenhe were $32.36 \%$ and $32.08 \%$, respectively. The variation of drought intensity in Heilongjiang Province was contrary to that of drought frequency. The drought intensity was small in areas with high drought frequency, but large in areas with low drought frequency. Drought events with high intensity were often rarer than those with small intensity. 

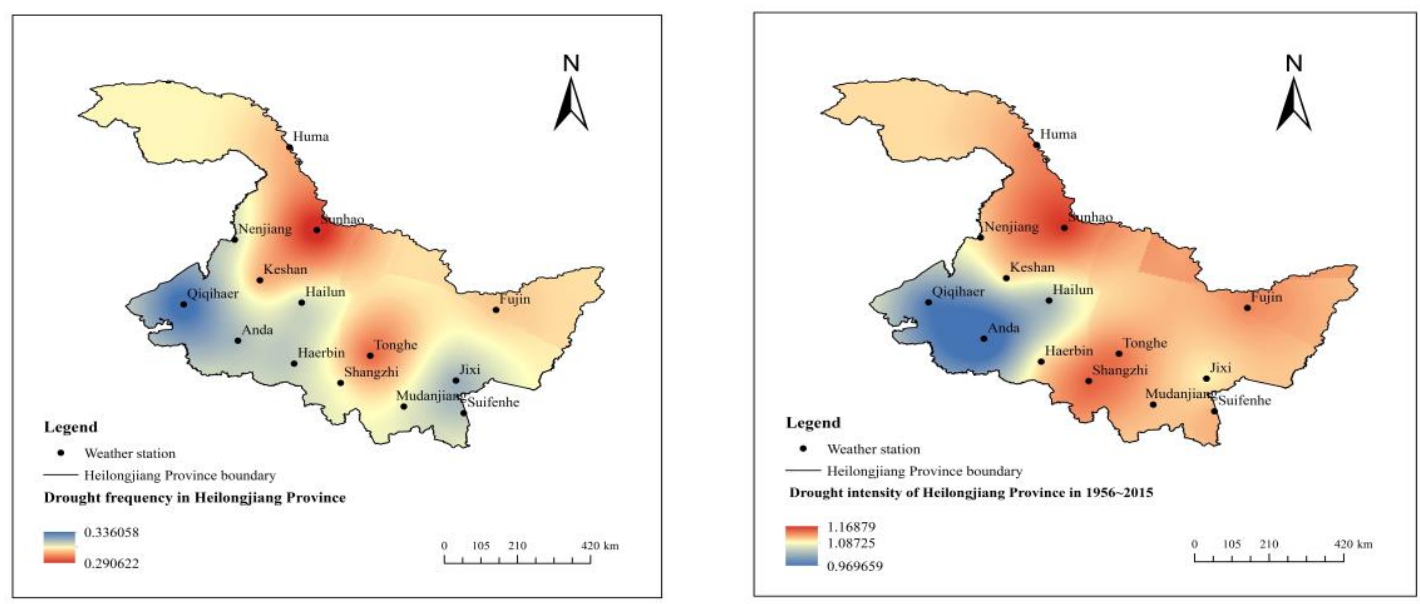

Figure 6. Drought frequency and intensity distribution map of Heilongjiang Province

\section{Spatial evolution of interdecadal drought}

According to the analysis of Figure 7a, in the 1956-1965 period, the Suifenhe River in the west and the Suifen River in the southeast formed the two most intense central points. In the 1966-1975s, one of the centers of gravity shifted, forming the central point of the Tonghe River in the south-central part and the Suifen River in the southeast. The overall drought intensity was characterized by weak southwest and strong southeast. From 1976 to 1986, the two central points of drought intensity were distributed on both sides of the East and West again, which was similar to the distribution from 1956 to 1965, but their scope was obviously expanded. The center of drought intensity in the West changed from one point of Nenjiang River to a larger enclosure formed by Nenjiang River, Sun Wu and Keshan, occupying the northwest of Xiaoxing'an Mountains. Moreover, the northern part of the Greater Khingan Range was also affected by the encirclement. The drought center in the south of China shifted from Suifen River to Mudanjiang area, which was not far from the southwest of Suifen River. In the 1986 1995 era, the southern drought intensity center continued to move westward to Harbin. The other drought intensity center moved from the northwest of the Xiaoxing'an Mountains in the last decade to Fujin in the eastern part of Heilongjiang Province, and almost covered the whole Sanjiang Plain area with Fujin as the center. Since 1996, global warming has caused long-term persistence in the Heilongjiang region to be affected by high temperatures, and the spatial distribution of drought intensity has changed significantly. In the decade from 1996 to 2005, the lowest drought intensity in Heilongjiang Province jumped from the previous drought to moderate drought, and formed the two major centers of Sun $\mathrm{Wu}$ and Tonghe. The high drought intensity ranged over the severe situation in central Heilongjiang Province. In the 20062015 period, the high drought intensity distribution area of Heilongjiang Province has spread throughout the province, gradually increasing from south to north. Different from the local point distribution in the previous high-intensity intensity areas, during this period, the drought intensity was generally above the moderate drought, and the higher drought intensity range has been extended to the province. The drought frequency distribution (Fig. 7b) of 14 meteorological stations in Heilongjiang Province from 1956 to 2015 was relatively stable, basically fluctuating around 30\%, and the drought frequency of 14 stations showed similar distribution patterns in each age. 

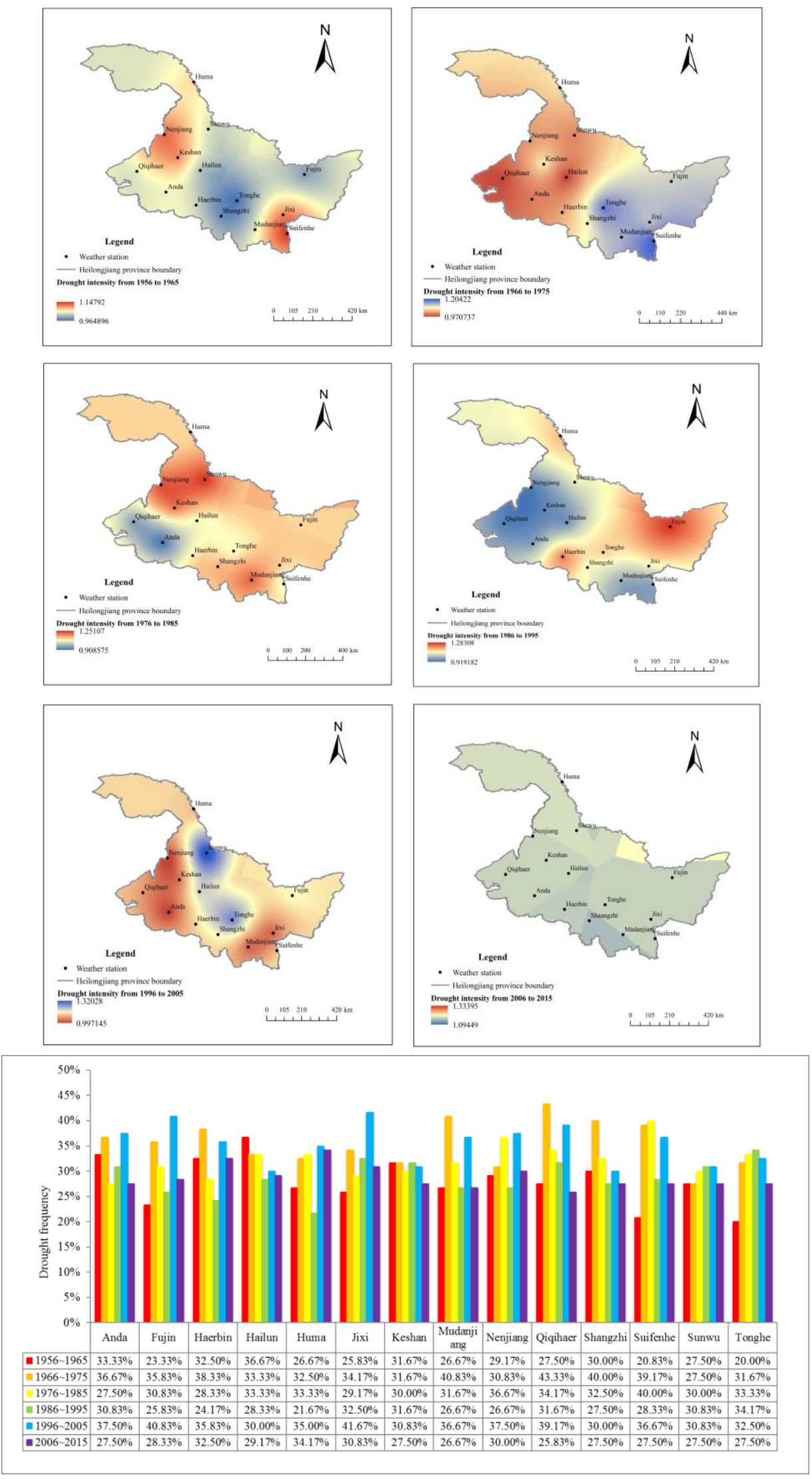

b

Figure 7. (a) Spatial evolution map of interdecadal drought in Heilongjiang Province; (b) interdecadal drought frequency histogram of Heilongjiang Province 


\section{Spatial distribution of seasonal drought}

It can be seen from Figure $8 a$ that the intensity of drought in Heilongjiang Province was generally large and the distribution was the widest. The areas with high drought intensity were mainly concentrated in the central and southeastern mountainous areas, the Daxing'an Mountains in the north and the west of Nenjiang River. The plains have alleviated the drought to some extent due to the pooling of rivers and snow and ice. The two major centers with higher drought intensity in summer were Sun Wu in the north of Xiaoxing' an Mountains and Fu Jin in the north of Sanjiang Plain, and the drought intensity was strong in the north and weak in the southeast. This was due to the influence of the southeast monsoon in Heilongjiang Province in summer, which lead to more precipitation in Southeast China. The Wanda Mountain in the East and the mountains in the middle of Heilongjiang Province blocked the intrusion of warm and humid air currents, which formed a typical monsoon precipitation distribution in summer. The distribution pattern of drought intensity in autumn in Heilongjiang Province was similar to that in the past 60 years. Nenjiang-Sunwu-Keshan and Mudanjiang-Suifenhe were the two high drought intensity centers, which were moderate drought, and other areas were light drought. The distribution of drought intensity in Heilongjiang Province in winter was closely related to the 60-year average precipitation distribution. The drought intensity of the Shangzhi-Tonghe area with large precipitation was large, while the QiqiharAnda area with less precipitation had less drought intensity. This was due to the cold weather in Heilongjiang in winter, which caused the river to freeze, affecting the water cycle, and the precipitation was also reduced to the lowest in the four seasons. The Heilongjiang region was sensitive to drought due to its complex topography and water system. The area with more average precipitation had more water demand, so it was more sensitive to the lack of water and formed a higher drought intensity. It can be seen from Figure $8 b$ that the drought frequency distribution of the four seasons in Heilongjiang Province was relatively uniform, and the drought frequency of the four stations in the four stations was stable at around $30 \%$.

\section{Discussion}

\section{Impacts of topography and basic meteorological elements on the formation of drought}

The uneven precipitation, sandstorm and uneven distribution of evaporation caused by the monsoon in Heilongjiang Province are the main meteorological factors for the formation of drought in the province. The precipitation in Heilongjiang Province is greater in the east than that in the west, but the sand and evaporation are both greater in the west than those in the east. This is affected by the temperate continental monsoon climate of Heilongjiang Province. The humid monsoon in the southeast of summer is blown in from the southeast, but it cannot be penetrated inland by the middle and southern mountains (Zhou et al., 2011). In the winter and spring, the dry monsoon from south of Siberia carries the sands of Mongolia from Songnen Plain to the west of the central mountains. This has led to an increase in evaporation and increased drought in the western region. Based on the above factors, the overall drought frequency in Heilongjiang Province is higher than that in the east. 

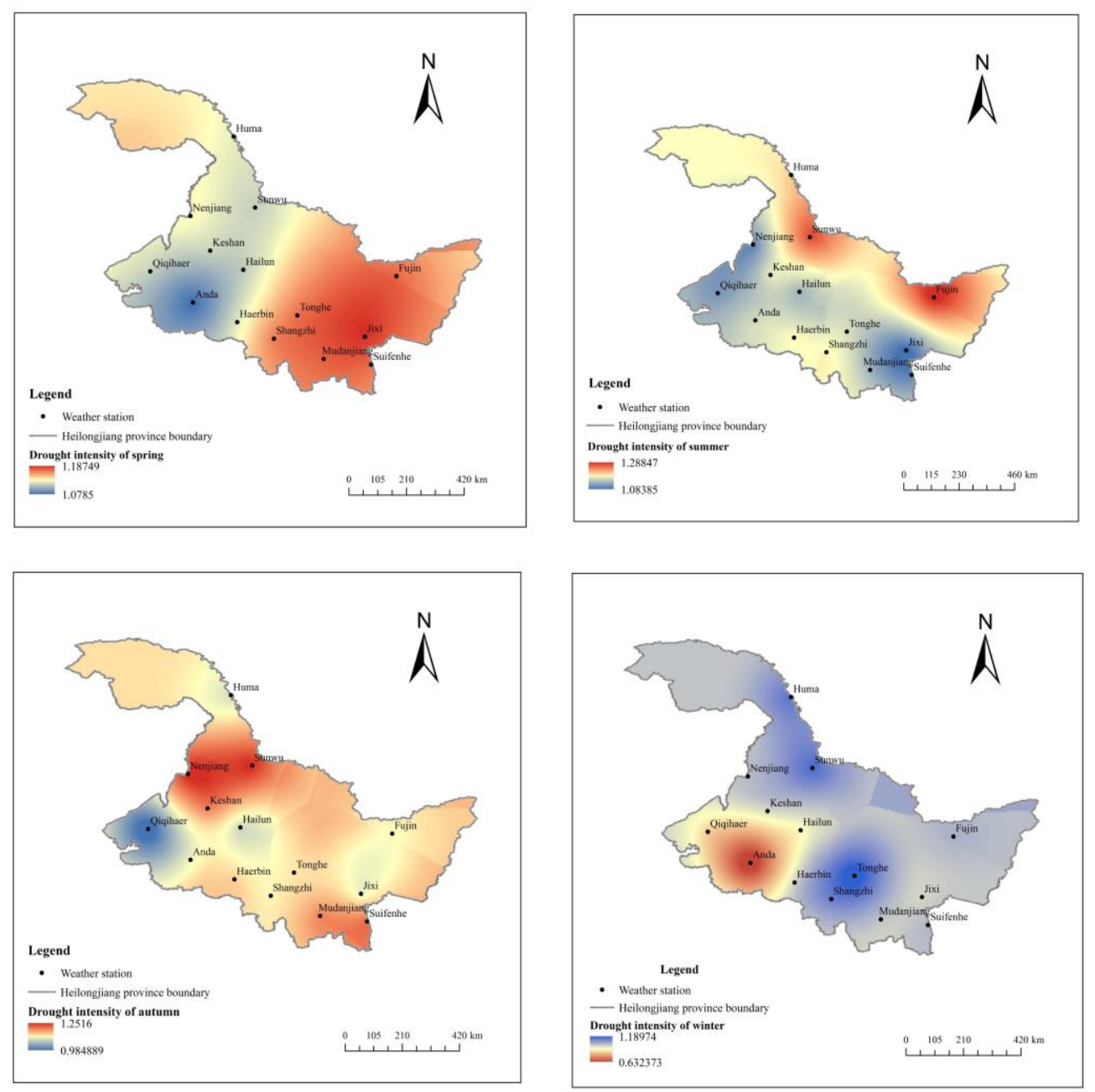

a

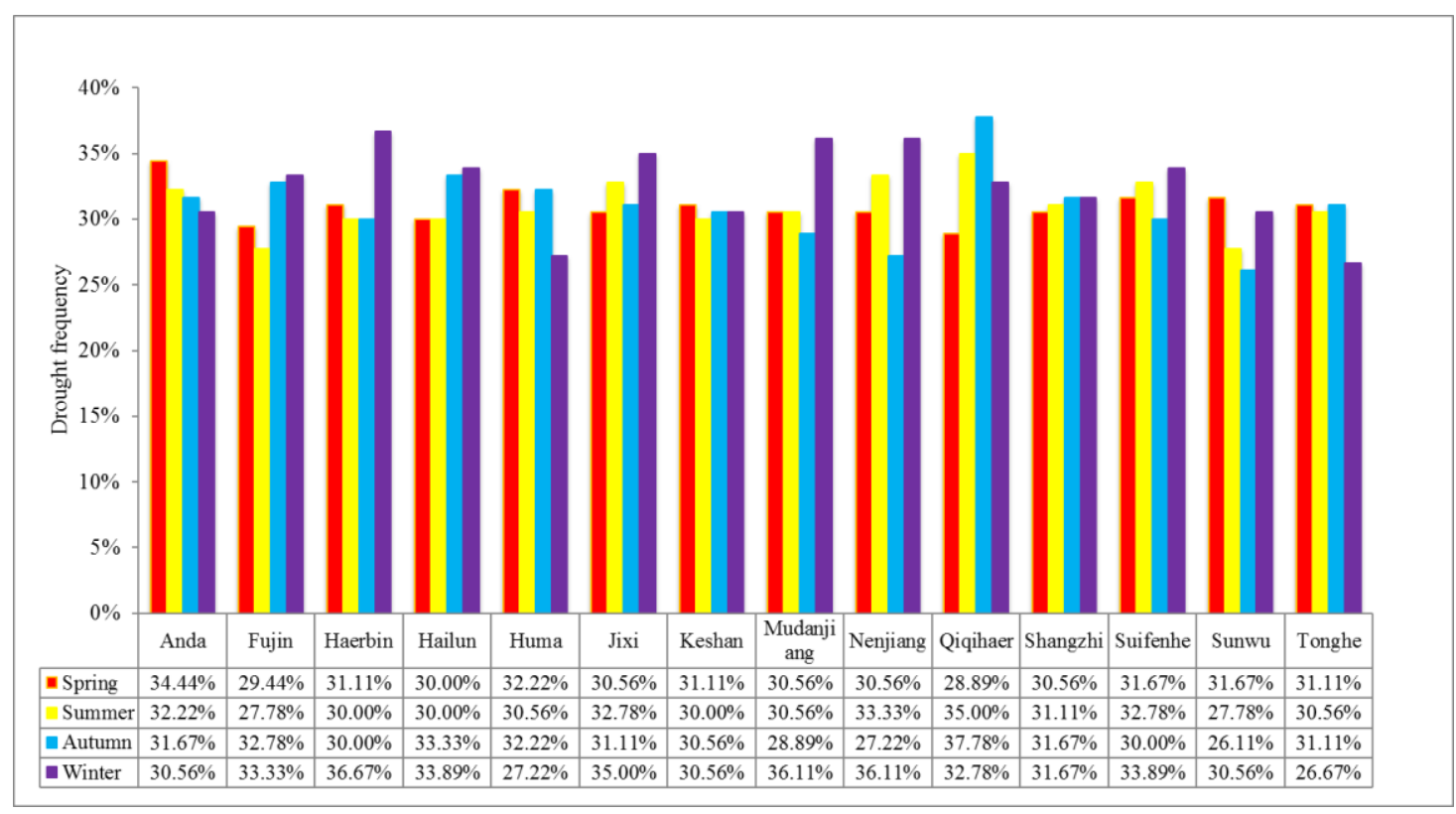

b

Figure 8. (a) Spatial distribution map of four seasons drought intensity in Heilongjiang Province. (b) Histogram of four seasons drought frequency in Heilongjiang Province 


\section{Interannual climate anomaly signals affecting drought in northern China}

There are many complex factors which affect the climate change in northern China. Since summer precipitation in most parts of China accounts for the majority of total annual precipitation, the interannual anomaly signals affecting summer precipitation in China are discussed. Analysis of factors affecting summer precipitation include sea surface temperature (ENSO phenomenon), snow cover, ground temperature and other underlying surface thermal factors and Asian monsoon, tropical convection, equatorial convergence, cross-equatorial flow, Qinghai-Tibet high, western Pacific subtropical high, Mid-latitude block high pressure, polar vortex, teleconnection type, quasi-twoyear oscillation (QBO), three major oscillations and other atmospheric activity centers or atmospheric circulation systems, as well as solar activities, astronomical factors, geophysical factors, etc. (Chen et al., 2001; Wang et al., 2005; Sha et al., 2013; Feng et al., 2014). These factors cover a wide range of aspects, including not only the Earth system ocean circle, the ice and snow circle, the atmosphere, the lithosphere, but also the solar activities outside the Earth system.

\section{Impacts of climate warming and atmospheric circulation on drought}

Studies have shown that precipitation in a particular place has a certain relationship with changes in atmospheric circulation (Yan and Zhang, 1994; Salinger and Mullan, 1999; Ramadan and Beighley, 2012). From the atmospheric circulation situation, it can be seen that there are significant differences between the rainy and rainy periods. During the rainy period, in the middle and high latitudes of East Asia, the westerly winds of the westerly winds are large, the high pressure of Yakutsk is strong and stable, and there is a clear north ridge in the eastern part of Lake Baikal, so that the eastern part of the northeast is at the front of the average trough of the south branch. Frequent low pressure and cold vortex move eastward, forming rainy weather and increasing precipitation. On the contrary, there is less precipitation (Sun and Zhou, 2010; HanssenBauer, 2015).

The precipitation in Heilongjiang showed a significant downward trend in the 60 years of 1956 2015. After 1990s, there was a sharp decline in large-scale drought. The persistent drought in these years is closely related to the background of global warming. Global warming is an important reason for the frequent drought in Heilongjiang after the 80 s of last century. Sustained high temperature makes the arid area enlarged; the surface evaporation increased; the soil organic matter decreased; the wetland area narrowed, destroyed the ecological diversity and stability of Heilongjiang Province, made the ecological climate environment of Heilongjiang Province fragile, land desertification, salinization, desertification greatly aggravated. Therefore, Heilongjiang is more vulnerable to drought. In addition, the precipitation in Heilongjiang Province has almost the same interdecadal oscillation trend with atmospheric circulation, vorticity field and divergence field. Since the 1980s, the East Asian westerly circulation affecting Heilongjiang Province has a strong latitude, the Yakutsk high is weak, there is no polar vortex center in the eastern Ural Mountains, and the eastern part of Heilongjiang Province is under the Northwest Airflow behind the ridge-trough, which often leads to high temperature and drought weather. At this time, the north of China is in the situation of weakening the convergent updraft caused by the weakening of positive vorticity and stronger divergent subsidence caused by the weakening of divergence, which is not conducive to the formation of precipitation. 
The mechanism for the formation of the drought are complex, there are a lot of factors that impact worthy of further study, such as El Nino phenomenon, sunspot activity and Heilongjiang drought pending further analysis. Warm and cold years the drought disasters variation and related mechanism need to be further clarified.

\section{Conclusion}

1) The correlation between monthly mean precipitation and monthly mean temperature in Heilongjiang Province is apparent. The drought in Heilongjiang Province occurred during the year, but its intensity was relatively light and it was relatively stable. The seasonal drought frequency in Heilongjiang Province was negatively correlated with drought intensity.

2) The precipitation in Heilongjiang Province in the whole 60 years showed a downward trend, but the downward trend was not significant, and the overall situation was relatively stable. Interdecadal precipitation fluctuated greatly, with two large declines in the 1960s and 1990s, and a very significant drop in 1961. Although the frequency of drought has been fluctuating greatly, the overall trend of 60 years has remained basically the same. The intensity of drought is fluctuating and the intensity is between mild drought and moderate drought.

3) The distribution of drought frequency in Heilongjiang Province is the lowest in Xiaoxing'anling in the central part and the Songhua River and Mudanjiang in the south, the highest in the Songnen Plain in the west. The spatial distribution of drought frequency in Heilongjiang Province is relatively stable in 60 years, and it basically fluctuates around $30 \%$. The interdecadal drought intensity shows a periodical cycle of localized point-like distribution with strong intensity in the eastern and western regions in the previous decade and strong intensity in the eastern part of the decade. Since the 1990s, the intensity of drought in the entire central region has increased. After entering the 21 st century, the distribution of higher drought intensity has spread throughout the province, and the lowest intensity has reached moderate drought, and gradually increased from south to north.

4) The intensity of drought in Heilongjiang Province is generally large and the distribution is the widest. In the other three seasons, only local areas have greater drought intensity. The drought frequency distribution of the four seasons in Heilongjiang Province is relatively uniform, and the drought frequency of the four weather stations in the four seasons is stable at around $30 \%$.

5) The uneven precipitation, sand and evaporation distribution caused by the monsoon in Heilongjiang Province are the main meteorological factors for the formation of drought in the province. Global warming is an important reason for the frequent drought in Heilongjiang after the 1980s. Heilongjiang Province is prone to high temperature and dry weather due to the influence of the East Asian Westerly circulation, the Yakutsk high pressure and the northwest airflow. Moreover, the weaker positive vorticity caused by the weaker positive vorticity in Heilongjiang Province and the weaker divergence caused by the divergent downdraft flow are not conducive to the formation of precipitation.

The climate of Heilongjiang Province has the typical characteristics of the northeast region. Its temperature change and extreme weather events in recent years have been some change, and its causes are still unable to be defined. The aim of research in the 
future is seeking the regional disaster response to the global climate change and mechanism between them.

Acknowledgements. We express our sincere appreciation to the anonymous reviewers for their constructive suggestions. The work was supported by the special program for the National Natural Science Foundation of China $(41471160,41602356)$. The authors would also to thank the reviewers for their very valuable comments, which greatly improved the quality of the paper.

\section{REFERENCES}

[1] Blauhut, V., Gudmundsson, L., Stahl, K. (2015): Towards pan-European drought risk maps: quantifying the link between drought indices and reported drought impacts. Environmental Research Letters 10(1): 014008.

[2] Chang, Y., Han, J. W., Chang, L. Q. (2012): Spatial and temporal change characteristics of rainstorm over Hulun Buir in the recent 40 years. - Torrential Rain and Disasters 31(4): 379-383.

[3] Chen, G., Zhang, P., Xu, L. (2001): Preliminary studies on the cause of southern flood and northern drought during the summer of 1999 in China. - Climatic and Environmental Research 6(3): 312-320.

[4] Corti, T., Wüest, M. et al. (2011): Drought-induced building damages from simulations at regional scale. - Natural Hazards and Earth System Sciences 11(12): 3335-3342.

[5] Du, J., Fang, J., Xu, W., Shi, P. (2013): Analysis of dry/wet conditions using the standardized precipitation index and its potential usefulness for drought/flood monitoring in Hunan province, China. - Stochastic Environmental Research and Risk Assessment 27(2): 377-387.

[6] Guhathakurta, P., Menon, P., Inkane, P. M., Krishnan, U., Sable, S. T. (2017): Trends and variability of meteorological drought over the districts of India using standardized precipitation index. - Journal of Earth System Science 126(8): 120.

[7] Hanssen-Bauer, I., Eirik, J. F. (2000): Temperature and precipitation variations in Norway 1900-1994 and their links to atmospheric circulation. - International Journal of Climatology 20(14): 1693-1708.

[8] Hao, Z. X., Zheng, J. Y., Wu, G. F., Zhang, X. Z., Ge, Q. S. (2010): 1876-1878 severe drought in North China: Facts, impacts and climatic background. - Science Bulletin 55(26): 3001-3007.

[9] Jiang, L., An, P. (2011): Temporal and spatial distribution and grain risk assessment of natural disasters in China. - Journal of Catastrophology 26(1): 48-19.

[10] Kazemzadeh, M., Malekian, A. (2016): Spatial characteristics and temporal trends of meteorological and hydrological droughts in northwestern Iran. - Natural Hazards 80(1): $1-20$.

[11] Kim, S., Kim, H. S., Kwak, J., Kim, Y., Noh, H., Lee, J. (2015): Analysis of drought length using the BDS statistic and close returns test. - KSCE Journal of Civil Engineering 19(2): 446-455.

[12] Koutroulis, A. G., Vrohidou, A. E. K., Tsanis, I. K. (2011): Spatiotemporal characteristics of meteorological drought for the island of Crete. - Journal of Hydrometeorology 12(2): 206-226.

[13] Kumar, R., Musuuza, J., Teuling, A., Samaniego, L., Van Loon, A., Ten Broek, J., Barthel, R., Mai, J., Attinger, S. (2016): The Performance of the standardized precipitation index as a groundwater drought indicator. - Hydrology \& Earth System Sciences Discussions 12(8): 7405-7436. 
[14] Li, J., Chen, F., Cook, E. R., Gou, X., Zhang, Y. (2007): Drought reconstruction for north central China from tree rings: the value of the palmer drought severity index. International Journal of Climatology 27(7): 903-909.

[15] Lin, F., Li, T., Yu, W. D. (2014): Cause of severe droughts in Southwest China during 1951-2010. - Climate Dynamics 43(7-8): 2033-2042.

[16] Luo, Y., Liu, S., Fu, S. L., Liu, J. S., Wang, G. Q., Zhou, G. Y.(2008): Trends of precipitation in Beijiang River Basin, Guangdong Province, China. - Hydrological Processes 22(13): 2377-2386.

[17] Mckee, T. B., Doesken, N. J. (2015): An investigation of drought magnitude trend during 1975-2005 in arid and semi-arid regions of Iran. - Environmental Earth Sciences 73(3): 1231-1244.

[18] Mishra, A. K., Singh, V. P. (2011). Drought modeling - a review. - Journal of Hydrology 403(1): 157-175.

[19] Ngetich, K. F., Mucheru-Muna, M., Mugwe, J. N., Shisanya, C. A., Diels, J., Mugendi, D. N. (2014): Length of growing season, rainfall temporal distribution, onset and cessation dates in the Kenyan highlands. - Agricultural and Forest Meteorology 188: 2432.

[20] Okonkwo, C., Demoz, B., Onyeukwu, K. (2013): Characteristics of drought indices and rainfall in Lake Chad basin. - International Journal of Remote Sensing 34(22): 79457961.

[21] Patel, N. R., Chopra, P., Dadhwal, V. K. (2007): Analyzing spatial patterns of meteorological drought using standardized precipitation index. - Meteorological Applications 14(4): 329-336.

[22] Potop, V., Boroneant, C., Martin, M. (2014): Observed spatiotemporal characteristics of drought on various time scales over the Czech Republic. - Theoretical \& Applied Climatology 115(3-4): 563-581.

[23] Ramadan, H. H., Beighley, R. E. (2012): Inter-annual temperature and precipitation variations over the Litani Basin in response to atmospheric circulation patterns. Theoretical \& Applied Climatology 108(3-4): 563-577.

[24] Salinger, M. J., Mullan, A. B. (1999): New Zealand climate: temperature and precipitation variations and their links with atmospheric circulation 1930-1994. International Journal of Climatology 19(10): 1049-1071.

[25] Song, S., Singh, V. P. (2010): Meta-elliptical copulas for drought frequency analysis of periodic hydrologic data. - Stochastic Environmental Research \& Risk Assessment 24(3): 425-444.

[26] Spinoni, J., Naumann, G., Carrão, H., Barbosa, P., Vogt, J. (2014): World drought frequency, duration, and severity for 1951-2010. - International Journal of Climatology 34(8): 2792-2804.

[27] Sun, A., Gao, B. (2000): A diagnostic analyses of serious flood/drought during summer season in the north China plane. - Scientia Atmospherica Sinica 24(3): 393-402.

[28] Sun, Y., Zhu, W. J., Wang, Q. Q., Zhao, K. (2010): Variation of summer precipitation anomaly in North China and its relation with atmospheric circulation. - Trans Atmos Sci 33(1): 67-73.

[29] Wang, S. Y., Huo, Z. G., Zhou, Y. W., Yang, L. F. (2005): Risk regionalization of winter wheat loss caused by drought in north of China. - Acta Agronomica Sinica 30(1): 60-65.

[30] Xi, Y., Fu, R., Shi, L., Zhang, J., Lin, D. N. (2014): Spatial analysis of the distribution, risk factors and access to medical resources of patients with hepatitis B in Shenzhen, China. - International Journal of Environmental Research \& Public Health 11(11): 11505-11527.

[31] Yan, H. S., Zhang, Q., You, W. H. (1994): Effect of atmospheric circulation variation on rainfall in May in Yunnan Province and its forecast. - Plateau Meteorology 13(2): 217223. 
[32] Yang, P., Xia, J., Zhang, Y., Wang, L. (2017): Drought assessment in northwest china during 1960-2013 using the standardized precipitation index. - Climate Research 72(1): 73-82.

[33] Yang, S. T., Ming, X. H., Zuo, Z., Nuist, S. (2013): Atmospheric circulation characteristics and cause analysis for autumn drought in the eastern region of southwest China. - Transactions of Atmospheric Sciences 36(5): 593-603.

[34] Yao, Y. B., Dong, A. X., Wang, Y. R., Zhang, X. Y., Yang, J. H. (2007): Compare research of the regional arid characteristic base on Palmer drought severity index in spring over China. - Arid Land Geography 30(1): 22-29.

[35] Yi, L., Yu, H., Ge, J., Lai, Z., Xu, X., Qin, L. et al. (2012): Reconstructions of annual summer precipitation and temperature in North-central China since 1470 ad based on drought/flood index and tree-ring records. - Climatic Change 110(1-2): 469-498.

[36] Yuan, W. P., Zhou, G. S. (2004): Theoretical study and research prospect on drought indices. - Advance in Earth Sciences 19(6): 982-991.

[37] Zhang, J. T., Feng, L. P., Pan, Z. H. (2014): Climate change trend and mutation analysis of Heilongjiang Province in the next 41 years. - Meteorological and Environmental Sciences 37(3): 60-66.

[38] Zhou, X. J., Na, J. H., Pan, H. S. (2011). Climatic characteristics and cause of summer drought in Heilongjiang Province. - Journal of Natural Disasters 20(5): 131-135. 